\title{
A Spanish version of the short Mathematics Anxiety Rating Scale
}

\section{(SMARS)}

M. Isabel Núñez-Peña ${ }^{1,2}$, Macarena Suárez-Pellicioni ${ }^{1,2}$, Georgina Guilera ${ }^{1,2}$ and Clara

$$
\text { Mercadé-Carranza }^{1}
$$

${ }^{1}$ Department of Behavioral Sciences Methods, Faculty of Psychology, University of Barcelona, Passeig Vall d'Hebron, 171, Barcelona, Spain

${ }^{2}$ Institute for Brain, Cognition and Behavior (IR3C), University of Barcelona, Passeig Vall d'Hebron, 171, Barcelona, Spain

\section{Correspondence to:}

Maria Isabel Núñez-Peña

Department of Behavioral Sciences Methods, Faculty of Psychology, University of Barcelona. Passeig Vall d'Hebron, 171. 08035 Barcelona (Spain). Tel.: +34-933125853.

Fax: +34-934021359. E-mail: inunez@ub.edu 


\begin{abstract}
The aim of this study was to adapt and assess the psychometric properties of the Spanish version of the sMARS in terms of evidence of validity and reliability of scores. The sMARS was administered to 342 students and, in order to assess convergent and discriminant validity, several subsamples completed a series of related tests. The factorial structure of the sMARS was analyzed by means of a confirmatory factor analysis and results showed that the three-factor structure reported in the original test fits well with the data. Thus, three dimensions were established in the test: math test, numerical task and math course anxiety. The results of this study provide sound evidence that demonstrates the good psychometric properties of the scores of the Spanish version of the sMARS: strong internal consistency, high 7-week test-retest reliability and good convergent/discriminant validity were evident. Overall, this study provides an instrument that allows us to obtain valid and reliable math anxiety measurements. This instrument may be a useful tool for educators and psychologists interested in identifying individuals that may have a low level of math mastery because of their anxiety.
\end{abstract}

Keywords: mathematics anxiety; mathematics education; assessment; factor analysis; psychometric properties 


\section{Introduction}

Mathematics anxiety is defined as "feelings of tension and anxiety that interfere with the manipulation of numbers and the solving of mathematical problems in a wide variety of ordinary life and academic situations" (Richardson \& Suinn, 1972, p. 551). Math anxiety has been demonstrated to have unfortunate consequences in terms of mastery of math. Math anxious individuals take fewer math courses, get lower grades in the classes they do take, and choose college majors that are less related to mathematics and the physical sciences than their low math anxiety counterparts (Ashcraft, Kirk \& Hopko, 2000). Moreover, higher mathematics anxiety consistently relates to negative attitudes toward mathematics, low enjoyment of mathematics and poor self-confidence in the subject. In a meta-analysis, Hembree (1990) reported a correlation of -.75 between math anxiety and enjoyment of math and a correlation of -.71 between math anxiety and self-confidence in math. Given that being able to manage numbers is essential in a modern society which demands a workforce well trained in technologies, mathematics anxiety has become a subject of increasing interest (Ashcraft, Krause \& Hopko, 2007; Ashcraft \& Ridley, 2005). In this sense it is especially important to develop instruments to measure math anxiety, not only for educational and clinical purposes, but also for researchers interested in investigating the cognitive consequences of mathematics anxiety.

Dreger and Aiken (1957) were the first to attempt to measure math anxiety. They added three math-related items to the Taylor Manifest Anxiety Scale (Taylor, 1953) and named it the Numerical Anxiety Scale. In 1972 Richardson and Suinn published a more complete instrument for measuring math anxiety, the Mathematics Anxiety Rating Scale (MARS). The MARS is a 98-item rating scale on which participants, using a 1 to 5 Likerttype scale, have to rate how anxious they would feel in situations involving numbers, 
ranging from formal math settings (e.g., opening a math textbook) to informal (everyday) situations (e.g., working out a restaurant bill they think was miscalculated). The score on the MARS is simply the sum of the ratings across all 98 items (range from 98 to 490). Due to the good psychometric properties of the MARS measurements (e.g., a 7-week test-retest reliability of .85 and an internal consistency reliability of .97 , reported in the original paper by Richardson and Suinn), the MARS has been adapted into many other languages and has become one of the most widely used instruments for measuring math anxiety. Moreover, the reliability and validity of scale scores has been frequently demonstrated (Alexander \& Cobb, 1989; Dew, Galassi \& Galassi, 1984; Plake \& Parker, 1982; Sloan, Slane, Ashcraft \& Fleck, 1994). Strong support for the reliability of the MARS scores was reported by Capraro, Capraro \& Henson (2001), who found that, across 28 studies, the MARS yielded scores with a mean internal consistency of .91 , and, across 7 studies, it yielded scores with a mean test-retest reliability of .84 .

Since the pioneering study by Richardson and Suinn (1972), other instruments have been developed to measure math anxiety: the 12-item Fennema-Sherman Mathematics Anxiety Scale (MAS; Fennema \& Sherman, 1976), the 6-item Sandman Anxiety Toward Mathematics Scale (ATMS; Sandman, 1980), the 24-item Math Anxiety Rating ScaleRevised (MARS-R; Plake \& Parker, 1982), the 25-item Abbreviated Math Anxiety Rating Scale (sMARS; Alexander \& Martray, 1989), the 9-item Abbreviated Math Anxiety Scale (AMAS; Hopko, Mahadevan, Bare \& Hunt, 2003) and the 23-item Mathematics Anxiety Scale-UK (MAS-UK; Hunt, Clark-Carter \& Sheffield, 2011). The main advantage of all these instruments is that they are shorter version, less time-demanding than the original MARS. Although many English version instruments are available to measure math anxiety, a Spanish version has not yet been created. This study was designed to address the issue by 
adapting the sMARS (Alexander \& Martray, 1989) into Spanish. We decided to adapt this instrument for two reasons: (a) of the all mathematics anxiety tests, until now the sMARS has been the most frequently employed as a mathematics anxiety test in the literature, and (b) as indicated by the scale developers it is supposed to measure three math anxiety dimensions that are not available in other math anxiety tests. The sMARS is a 25 -item scale which has been demonstrated to be an adequate alternative to the 98 -item MARS (Alexander \& Martray, 1989). The sMARS correlated .93 with the MARS and had a twoweek test-retest reliability of .86. Factor analysis revealed three underlying factors in the sMARS: (a) math test anxiety, defined by 15 items that reflect apprehension about taking a test in mathematics or about receiving the results of mathematics tests; (b) numerical task anxiety, defined by 5 items that reflect anxiety about carrying out numerical operations; and (c) math course anxiety, defined by 5 items that reflect anxiety about math classes.

Coefficient alpha was .96 for Factor I, .86 for Factor II, and .84 for Factor III.

The purpose of this study was to adapt and study the psychometric properties of the scores on a Spanish-language version of the sMARS for a university population. Specifically, we were interested in evaluating the following aspects: (a) factor structure, (b) corrected item-total correlations, (c) internal consistency, (d) 7-week temporal stability, and (e) convergent and discriminant validity. In order to study the relationship between the sMARS scores and other related measures, participants were administered a series of tests: the State-Trait Anxiety Inventory (STAI; Spielberger, Gorsuch, Lushene, Vagg \& Jacobs, 1983), three scales (Spatial Visualization, Reasoning Ability and Verbal Ability) from the Thurstone's Primary Mental Abilities Test (PMA; Thurstone, 1939), the Addition and Subtraction Verification Test from the French kit (French, Ekstrom \& Price, 1963), and a Single-digit Addition Test created by us for the present study. A short questionnaire to 
obtain information about participants' attitudes toward mathematics (degree of enjoyment, motivation and self-confidence in mathematics) was administered and information about their high-school itinerary ${ }^{1}$ was also collected. Subjects had to indicate whether they had previously graduated from high school with a concentration in social science, science, humanities, technology or other. The first two itineraries have very little mathematical content, while the last two involve a great deal of mathematics and calculation.

According to previous studies, mostly integrated in Hembree's meta-analysis (1990), we expected the following results: (a) a moderate negative correlation between math anxiety and the scores in the Addition and Subtraction Verification Test from the French kit, which allows us to measure arithmetic performance in multi-digit additions and subtractions; (b) a low relation between math anxiety and the score in the Single-digit Addition Test, because according to Ashcraft and colleagues (Ashcraft et al., 2000; Ashcraft \& Faust, 1994; Faust, Ashcraft \& Fleck, 1996) math anxiety has a low impact in simple additions performance; (c) moderate positive correlations between math anxiety and trait and state anxiety; (d) a moderate negative correlation between math anxiety and spatial ability; (e) a low correlation between math anxiety and reasoning ability ${ }^{2}$; (f) no relation between math anxiety and verbal ability; and $(\mathrm{g})$ strong inverse correlations between math anxiety and the degree of enjoyment, motivation and self-confidence in mathematics.

Finally, we expected females to have higher mathematics anxiety than males (Hembree,

\footnotetext{
${ }^{1}$ Itinerary refers to the concentration or area of interest during high-school studies ("Bachillerato" in Spanish), thus before enrolling in University. In the Spanish educational system, students graduate from high school with a concentration in one of the following areas: social science, science, humanities, technology or other.

2 There is increasing agreement that intelligence testing can be usefully approached through tests of inductive reasoning, which is acknowledged as being a central element in intelligence (Boyle, 1987). Gustafsson (1988) has demonstrated that general ability (G), general fluid ability (Gf) and inductive reasoning ability (IR) are synonymous and he says we can measure essential aspects of " $G$ " by measuring inductive reasoning abilities. Given that the reasoning ability subtest from the PMA measures inductive reasoning, we have taken it as a measure of intelligence. According to Hembree (1990), higher mathematics anxiety was slightly related to lower IQ levels.
} 
1990; Hyde, Fennema, Ryan, Frost \& Hopp, 1990), and individuals who follow social science and humanities to have higher mathematics anxiety than those who course technology and science (LeFevre, Kulak \& Heymans, 1992).

\section{Material and methods}

\subsection{Participants}

The participants were 342 undergraduate students from the University of Barcelona (Spain) who completed the sMARS test as part of a voluntary class activity (women, $n=$ $261,76.31 \%$; men, $n=81,23.68 \%)$. The mean age was 20.79 years $(S D=3.32$, range $=$ 18-43) for women and 21.21 years $(S D=2.64$, range $=19-32)$ for men. All participants were first and second year Bachelor students majoring in Psychology, and had previously graduated from high school with a concentration in social science (37.7\%), science (27.3\%), humanities (23.1\%), technology $(7.7 \%)$ or other $(4.2 \%)$. Mean and standard deviation for age and sMARS scores for the sample disaggregated by gender and highschool itinerary as well as the percentage of sample for each category are shown in Table 1. Participants were recruited using opportunity sampling from various lectures and practice seminars. The retest sample consisted of an opportunity sample of 104 students of the original sample (women, $n=84$, mean age $=20.70, S D=3.01$, range $=18-40$; men, $n$ $=20$, mean age $=21.37, S D=2.96$, range $=19-28)$ who completed the sMARS 7 weeks after the first administration in order to study test-retest reliability. All participants gave written consent after being informed of the purpose of the study.

Psychometric properties of sMARS scores were evaluated in four opportunity subsamples, all of them proceeding from the original one: Subsample 1 (women, $n=148$, mean age $=20.82, S D=3.29$, range $=18-43 ;$ men, $n=41$, mean age $=21.20, S D=$ 2.51 , range $=19-28$ ); Subsample 2 (women, $n=36$, mean age $=19.53, S D=2.00$, 
range $=18-26 ;$ men, $n=14$, mean age $=19.71, S D=0.72$, range $=19-21)$;

Subsample 3 (women, $n=21$, mean age $=21.52, S D=2.60$, range $=18-27 ;$ men, $n=$ 7 , mean age $=22.71, S D=1.70$, range $=21-25)$; Subsample 4 (women, $n=18$, mean age $=20.39, S D=1.97$, range $=18-25 ;$ men, $n=4$, mean age $=22.75, S D=6.23$, range $=19-32$ ). The information collected in each subsample is described in the Instruments section.

Insert Table 1 approximately here

\subsection{Instruments}

sMARS (Alexander \& Martray, 1989). The sMARS is a 25-item version of the Math Anxiety Rating Scale (MARS; Richardson \& Suinn, 1972). This instrument measures anxiety by presenting 25 situations which may cause mathematical anxiety grouped into three factors: math test, numerical task and math course anxiety. Items are answered on a five-point Likert scale from 1 (no anxiety) to 5 (high anxiety). Since sMARS total score is obtained by summing each item rating, scores range between 25 and 125 . The test was back-translated into Spanish in order to apply it to the local population (more detail is given in the Procedure section). SMARS measurements were collected from all the subsamples.

Simple-arithmetic Test. This test consisted of 165 single-digit addition problems with the form $a+b=$ organized in five columns. It was administered with a time limit of two minutes that was not known to the subjects. The test was made up of twenty-four different single-digit additions (operands between 2 and 9). No addition included the numbers 1 or 0 due to evidence suggesting that problems including this numbers as addends are solved via rules rather than retrieval (Ashcraft, 1982). Tie problems (e.g., $4+$ 4) were also excluded. The score for the test was the number of correctly solved additions. Data were collected from subsamples 1,2 and 4. 
Addition and Subtraction Verification Test from the French kit (French, et al., 1963). This consists of a total of 60 two-operand additions and subtractions that have to be verified by saying whether a proposed result is correct or incorrect. Subjects are asked to verify as quickly and as accurately as possible during a 2-minute period. French kit data were collected from subsamples 2, 3 and 4 .

STAI (Spielberger, et al., 1983). The STAI is a 40 -item scale used to measure state (STAI-S) and trait (STAI-T) anxiety. Good to excellent internal consistency (Cronbach`s alpha $=.86-.95)$ and adequate test-retest reliability (State: $r=.71-.76$; Trait: $r=.75-.86$ ) has been reported (Spielberger et al., 1983). It includes 40 statements describing different emotions, 20 for each scale. Items are answered on a four-point Likert scale. In the STAI-S the answer options go from 0 (not at all) to 3 (very much) and subjects have to answer by taking into account how they feel "right now". In the STAI-T the answer options go from 0 (rarely) to 3 (almost always) and subjects have to answer by taking into account how they feel "in general". STAI measurements were collected from all the subsamples.

PMA (Thurstone, 1939). This test includes five subtests, but only three of them were used in this study: Spatial Visualization (S), Reasoning (R) and Verbal Comprehension (V). In the S subtest subjects have to look at a first figure (model) and then search for it among different rotated figures presented as answer options. The $\mathrm{R}$ subtest consists of a sequence of alphabet letters that have been ordered according to a certain criterion. Finally, in the V subtest subjects have to choose a synonym for a given adjective. PMA measurements were only collected from subsamples 3 and 4 because the administration of PMA is timeconsuming and we were unable to prolong the administration of the tests in some lectures.

Three additional questions about mathematical enjoyment (How much do you enjoy mathematics?), self-confidence (How much are you self-confident in mathematics?) and 
motivation (How much motivation do you have towards mathematics?) were presented on a five-point Likert scale from 1 (not at all) to 5 (very much). Answers to these questions were collected from subsamples 1, 2 and 4.

\subsection{Procedure}

The study began with the translation of the sMARS into Spanish (see Appendix 1). The process started with a preliminary Spanish version of the test, then this Spanish version was back-translated into English (English-2) by an English native, and finally another English native reviewed the two English versions of the test and the Spanish one. Both reviewers were North American, English teachers and have a high level of Spanish. We found a few discrepancies between the original English version and the English back-translation of the test in some items, and these were solved by consensus.

The questionnaires were administered in normal classroom settings. All participants were presented with the sMARS and different subsamples were presented with the other tests (subsample sizes are given in Table 4). A subsample of 103 students was tested again on the sMARS seven weeks after the first administration of the test.

\subsection{Data analysis}

The distribution of sMARS scores was evaluated obtaining means, standard deviations $(S D)$, observed range and percentage of students with missing values for factor and total scores.

A confirmatory factor analysis of the sMARS scores was carried out using the unweighted least squares estimation method, since data did not meet the assumptions of multivariate normality. A three first-order factor model with intercorrelations between factors was conducted to explore the fit of the underlying structure suggested by Alexander and Martray (1989) formed by three factors labeled math test anxiety, 
numerical task anxiety and math course anxiety. Chi-square statistic $\left(\chi^{2}\right)$, goodness of fit index (GFI), adjusted goodness of fit index (AGFI), parsimony goodness of fit index (PGFI), normed fit index (NFI) and standardized root mean squared residual (SRMR) were reported, and the model's goodness-of-fit was evaluated following these criteria (Hu \& Bentler, 1999; Jackson, Gillapsy \& Purc-Stephenson, 2009; Mulaik, James, Van Altine, Bennett, Lind \& Stilwell, 1989; Schumacker \& Lomax, 2004): a) $\chi^{2} p>.05$; b) GFI, AGFI and NFI $\geq .95 ; \mathrm{c})$ PGFI $\geq .60$; and d) SRMR $\leq .08$.

The reliability of the sMARS measures was examined with an assessment of internal consistency by means of Cronbach's alpha coefficient computation, obtaining corrected item-total correlations for the three subscales and the total score. Test-retest reliability was assessed with intra-class correlation coefficient (ICC) between the sMARS administered at the two different time points, under the two way mixed model.

In order to provide evidence of convergent and discriminant validity of sMARS scores as a measure of the construct of the mathematics anxiety level, the other measures previously described were related to sMARS responses using the Pearson correlation coefficient, and the Fisher's $Z$ test was used to assess the difference between correlations (Steiger, 1980). Known groups were defined by gender and high-school itinerary in order to assess the ability of the sMARS scores to differentiate between groups, and their scores on the three subscales and the total sMARS were compared by using $t$-tests or analyses of variance (ANOVA) where appropriate. When the homogeneity of variance assumption underlying the usual ANOVA was not satisfied, the test statistic developed by Welch (1951) was used. In order to compare groups in terms of previously taken itinerary, post hoc comparisons were tested by using Tukey's HSD (1953) or Games-Howell (1976) procedures (this last procedure was used when homogeneity of variance could not be 
assumed). The magnitude of these differences was assessed with standardized mean difference $(d)$ computing the mean difference between the two groups divided by the pooled standard deviation.

Participants with missing data were not excluded from the sample (within each subsample, percentage of cases with missing values was very low and no patterns were observed) and analyses were carried out with the available information by means of SPSS version 17.0 and AMOS version 18.0, setting statistical significance at $\alpha=.05$.

\section{Results}

\subsection{Distribution of scores}

The descriptive statistics for subscale and total scores are shown in Table 2.

\section{Insert Table 2 approximately here}

If the percentage of participants with the lowest score (no math anxiety) is very high then we have what is known as floor effect, which may indicate that the capacity of the sMARS to discriminate between levels of anxiety is questionable when the level of math anxiety is very low. In this study, the number of participants with the lowest possible score was $1(0.3 \%), 85(24.9 \%)$ and $60(17.5 \%)$ respectively for math test anxiety, numerical task anxiety and math course anxiety. In the case of the sMARS total score, only one participant $(0.3 \%)$ with the minimum score of 25 was observed. Regarding possible ceiling effects (consisting of seeing a high percentage of participants with the highest possible score), there was one student who got the maximum score in the math course anxiety subscale. However, it is worth knowing that the distribution of sMARS scores covered almost the total possible range, both in the subscales and the total scores. 
The very low percentage of participants with missing data indicates that the feasibility and acceptability of the sMARS is satisfactory when applied to university students.

\subsection{Factor structure}

The results from the confirmatory factor analysis of the sMARS are shown in Table

3. The obtained fit indexes for the three first-order factor model were $\chi^{2}(272)=841.169(p$ $<.05), \mathrm{GFI}=.969, \mathrm{AGFI}=.963, \mathrm{PGFI}=.811, \mathrm{NFI}=.961$ and $\mathrm{SRMR}=.080$. With the exception of the $\chi^{2}$ measure, which is sensible to sample size and $\chi^{2}$ centrality (Byrne, 2010), these indices suggest that the model fits the data, thus confirming that the underlying structure of the sMARS is formed by three factors that assess math test, numerical task and math course anxiety. Standardized factor loadings were higher than .45 , showing that all items are relevant in defining the corresponding domain. A strong relationship was observed between math test anxiety and math course anxiety $(r=.72, p<.001)$. Similarly the correlation coefficient between math test anxiety and numerical test anxiety was .54 ( $p$ $<.001)$, and between numerical test anxiety and math course anxiety $.57(p<.001)$.

Insert Table 3 approximately here

\subsection{Internal consistency and temporal stability}

As shown in Table 2, Cronbach's alpha coefficients were .93 for math test anxiety, .88 for numerical task anxiety and .85 for math course anxiety, with the corresponding corrected item-total correlations greater than .35 in all items. In the case of the sMARS total score, Cronbach's alpha reached a value of .94, again with high corrected item-total correlations with the exception of item 16 (Reading a cash register receipt after your purchase - Revisar el ticket de compra después de haber pagado) where a correlation 
coefficient of .32 was observed. These results indicate that the sMARS scores present excellent internal consistency (Kline, 2000) when applied to a university student sample. Regarding measure stability, the ICC value for the sMARS total score was .72, indicating that test-retest reliability after seven weeks is good, and subscale ICCs ranged from .56 for numerical task anxiety to .73 for math test anxiety, showing moderate to high values of test-retest reliability.

\subsection{Relations with other variables}

Relations between the sMARS and the other measures produced the correlations specified in Table 4. The directions and magnitudes of these correlations were as predicted and some merit special attention. First, math anxiety and math achievement, measured by the French kit verification test, showed a moderate negative correlation $(r=-.32)$, which indicates that the higher the math anxiety the lower the achievement in multi-digit additions and subtractions. Similar negative correlations, ranging from $r=-.26$ to $r=-.38$, were found between the verification test and the three math anxiety subscale scores. Second, a very small negative correlation $(r=-.13)$ was found between the single-digit addition task and the sMARS total scores, and the same correlation value was found when the singledigit addition scores were correlated with those of math test and numerical task anxiety. No relationship was found between simple addition task performance and math course anxiety. Third, state and trait anxiety was moderately related both to the sMARS total score $(r=.46$ for STAI-S and $r=.37$ for STAI-T) and to the three subscale scores (values ranged from $r$ $=.27$ to $r=.43$ ): highly math-anxious individuals also tend to have high state and trait anxiety. Fourth, math anxiety measured by means of the total sMARS and the math test and math course anxiety subscales was negatively correlated with spatial ability (correlation values from $r=-.24$ to $r=-.32$ ); however, the correlation between numerical task anxiety 
and spatial ability was lower and non-significant. In order to study differences between these three correlations we conducted comparisons between two dependent correlations. This analysis showed that the three correlations were not statistically different (see Table 5). Fifth, no relation was found between verbal ability and the sMARS total score $(r=-.11)$ and the math test and numerical task anxiety scores ( $r=-.05$ and $r=.06$, respectively). However, verbal ability was negatively related to math course anxiety $(r=-.21)$. Again, comparisons between correlations showed that they did not differ significantly (see Table 5). Finally, moderate to high negative correlations ranging between $r=-.36$ and $r=-.54$ were found between math anxiety scores and the degree of mathematical enjoyment, selfconfidence and motivation.

Insert Table 4 approximately here

Insert Table 5 approximately here

When analyzing the sMARS scores by gender and high-school itinerary, the mean scores and standard deviations shown in Table 6 were observed. As expected, women showed higher levels of anxiety than men, and statistically significant differences were found in math task anxiety $(t(334)=2.470, p=.011)$ and the total sMARS score $(t(329)=$ $2.395, p=.017)$. The magnitude of effects in the differences between men and women were low, i.e. $d=.33, .20$ and .14 respectively for the three sMARS subscales and .31 for total score.

Insert Table 6 approximately here

Regarding the itinerary, in all math anxiety scores itineraries were ordered from high to low level of anxiety as follows: humanities, social science, science and technology. Statistically significant differences were found for math task anxiety $(F(4,253)=11.325, p$ 
$<.001)$, numerical task anxiety (Welch's $F(4,52.9)=10.160, p<.001)$ and math course anxiety (Welch's $F(4,53.3)=8.139, p<.001)$, and also for the sMARS total score $(F(4,249)=12.264, p<.001)$. Post-hoc comparisons showed the statistical significances specified in Table 7, with statistically significant comparisons in italics. It is worth highlighting that individuals that had chosen humanities showed higher levels of math anxiety (measured both in the sMARS total score and in the subscale scores) than individuals that had chosen science and technology. Higher levels of math anxiety were also found in individuals that had chosen a social science itinerary compared to those reported to have chosen the technological one. Interestingly, noteworthy effect sizes were found in: i) humanities vs technology $(d=1.54)$, social vs technology $(d=1.29)$ and technology vs others $(d=-1.68)$ for math test anxiety, ii) humanities vs technology $(d=$ $1.08)$ and technology vs others $(d=-1.21)$ for numerical task anxiety, iii) humanities vs technology $(d=0.89)$ and technology vs others $(d=-1.24)$ for math course anxiety, and finally iv) humanities vs technology $(d=1.62)$, social vs technology $(d=1.29)$, science vs others $(d=-0.85)$ and technology vs others $(d=-1.81)$ for the sMARS total score.

Insert Table 7 approximately here

\section{Discussion}

The aim of this study was to examine the psychometric properties of the scores on a Spanish-language version of the sMARS. Math anxiety has become a subject of increasing interest in educational and clinical settings because of its consequences in reducing mastery of math, and a Spanish test for measuring this construct had not yet been developed. We decided to adapt the sMARS (Alexander \& Martray, 1989) into Spanish because this instrument has been widely used and good psychometric properties of its scores and interpretations have been demonstrated. Moreover, it includes three subscales that are not 
present in other math anxiety tests, enabling us to separate math test, numerical task and math course anxiety. To our knowledge this is the first time that the three sMARS subscales have been studied in more detail.

Confirmatory factor analysis provided evidence for the underlying structure of the sMARS proposed by Alexander and Martray (1989). Fit indexes of the three first-order factor model were excellent and factor loadings for the items on the three subscales were high, suggesting that the three dimensions established in the original sMARS (math test, numerical task and math course anxiety) were also evident in the Spanish version.

The measures of the Spanish version of the sMARS showed excellent internal consistency both for the three subscales (Cronbach's alpha coefficients ranged from .85 to .93 for the math test, numeral task and math course anxiety subscales) and for the sMARS total score (Cronbach's alpha coefficient $=.94)$. These values are close to those reported by Alexander and Martray (1989) in the original test. Moreover, good 7-week test-retest reliability was also found for the complete sMARS scores and for the three subscales' scores, which provides evidence of the stability of the measures of the Spanish version of the SMARS.

Convergent validity evidence was also examined and the results were consistent with previous studies, most of them summarized in Hembree's meta-analysis (1990). High scores in the sMARS measurements were moderately related to low achievement in multidigit additions and subtractions, but showed little relationship with achievement in singledigit additions — it is worth noting that although this little relationship was statistically significant, it accounts for only $1.7 \%$ of the variance (Rosenthal \& Rosnow, 1984). Multidigit problems are generally considered as "complex arithmetic" because they are usually solved by means of hard calculation procedures, whereas single-digit additions are 
considered "simple arithmetic" because most people rely on fast direct retrieval from memory to solve them (LeFevre, Sadesky \& Bisanz, 1996). Our result agrees with that reported by Ashcraft and Faust (1994), who found that in simple arithmetic problems there were no math anxiety differences (high and low math-anxious individuals performed at the ceiling), but the math anxiety effect became obvious in more complex problems. These results may explain why highly math-anxious students get lower grades in their math classes. High scores in the sMARS responses were also negatively related to attitudes toward mathematics, enjoyment of mathematics and self-confidence in one's ability to do mathematics.

As regards the relationship between math anxiety and other psychological constructs, the sMARS scores were only moderately related to trait and state anxiety. Although individuals with high math anxiety also tend to show high state and trait anxiety, the correlation between both measures ranged between .35 and .46 for STAI-S and .27 and .37 for STAI-T, which demonstrated that math anxiety is a similar but separate construct from state and trait anxiety (as predicted by Dreger and Aiken, 1957). A moderate negative relation between math anxiety and spatial ability was also found, which may be due to the widely confirmed fact that number representation involves a spatial component (Hubbard, Piazza, Pinel \& Dehaene, 2005; Priftis, Piccione, Giorgi, Meneghello, Umiltà \& Zorzi, 2008). Finally, math anxiety was not related to verbal ability nor was the reasoning, as predicted (see Hembree's meta-analysis, 1990).

Discriminant validity evidence was also investigated. In line with previous studies (Hembree, 1990; Hyde et al., 1990), we found that females scored higher on math anxiety than males. Moreover, individuals who stated they had followed technology or science high-school itineraries had lower mathematics anxiety than those who followed social 
science or humanities. This result is in accordance with the fact that high math anxiety is related to students' intentions to enroll in fewer math courses and take fewer elective math courses (Hembree, 1990; Ashcraft et al., 2000). This result would also explain why math anxiety is related to students' choices of a college major, with those with higher math anxiety avoiding majors and careers that require a considerable math background (LeFevre, Kulak \& Heymans, 1992).

To conclude, the findings discussed here demonstrate that mathematics anxiety can be reliably and validly measured by the proposed Spanish version of the sMARS. Not only has the utility of the sMARS been demonstrated but also the effectiveness of the three subscales to measure math test, numerical task and math course anxiety. Strong reliability was evident both in terms of internal consistency and in a 7-week temporal stability and convergent and discriminant validity evidences were also clear for the subscales and the overall sMARS measurements. In summary, the present study provides a Spanish-language instrument for measuring math anxiety that may be a useful tool for educators and psychologists interested in identifying individuals that may have a low math achievement because of anxiety. Additionally, it may also be useful to researchers interested in studying the cognitive consequences of math anxiety. 


\section{Acknowledgements}

We would like to thank Eric Johnson and Jennifer Johnson for their help in the adaptation of the sMARS, and Cristina Galusca for her help in the English revision. This research was supported by grants PSI2009-10364 and BES-2010-036859 from the Spanish Ministry of Science and Technology and SGR2009-11 from the Generalitat de Catalunya. 


\section{References}

Alexander, L., \& Cobb, R. (1989). Identification of the dimensions and predictors of math anxiety among college students. Journal of Human Behavior and Learning, 4, 2532.

Alexander, L., \& Martray, C. (1989). The development of an abbreviated version of the Mathematics Anxiety Rating Scale. Measurement and Evaluation in Counseling and Development, 22, 143-150.

Ashcraft, M. H. (1982). The development of mental arithmetic: A Chronometric approach. Developmental Review, 2, 213-236.

Ashcraft, M. H., \& Faust, M. W. (1994). Mathematics anxiety and mental arithmetic performance: An exploratory investigation. Cognition and Emotion, 8, 97-125.

Ashcraft, M. H., \& Ridley, K. S. (2005). Math anxiety and its cognitive consequences: A tutorial review. In J. I. D. Campbell (Ed.), Handbook of mathematical cognition (pp. 315-327). New York: Psychology Press.

Ashcraft, M. H., Kirk, E.P., \& Hopko, D. (2000). On the cognitive consequences of mathematics anxiety. In C. Donlan (Ed.), The development of mathematical skills (pp. 175-196). New York: Psychology Press.

Ashcraft, M. H., Krause, J. A., \& Hopko, D. R. (2007). Is math anxiety a mathematical learning disability? In D.B. Berch and M.M.M. Mazzocco (Eds.), Why is math so hard for some children? The nature and origins of mathematical learning difficulties and disabilities (pp.329-348). Barlimore: Paul H. Brookes Publishing Co.

Boyle, J. (1987). Intelligence, Reasoning, and Language Proficiency. The Modern Language Journal, 71(3), 277-288. 
Byrne, B. M. (2010). Structural equation modeling with AMOS: Basic concepts, applications, and programming (2nd ed.). New York: Routledge.

Capraro, M. M., Capraro, R. M., \& Henson, R. K. (2001). Measurement error of scores on the mathematics anxiety rating scale across studies. Educational and Psychological Measurement, 61(3), 373-386.

Dew, K. M. H., Galassi, J. P., \& Galassi, M. (1984). Math anxiety: Relation with situational test anxiety, performance, physiological arousal, and math avoidance behavior. Journal of Counseling Psychology, 31, 580-583.

Dreger, R. M., \& Aiken, L. R. (1957). The identification of number anxiety in a college population. Journal of Educational Psychology, 48, 344-351.

Faust, M. W., Ashcraft, M. H., \& Fleck, D. E. (1996). Mathematics anxiety effects in simple and complex addition. Mathematical Cognition, 2(1), 25-62.

Fennema, E., \& Sherman, J. (1976). Fennema-Sherman Mathematics Attitudes Scales. JSAS Catalog of Selected Documents in Psychology, 6 (Ms. No. 1225).

French, J. W., Ekstrom, R. B., \& Price, L. A. (1963). Manual for kit of reference tests for cognitive factors. Princeton, NJ: Educational Testing Service.

Games, P. A., \& Howell, J. F. (1976). Pairwise multiple comparison procedures with unequal N's and/or variances: A Monte Carlo study. Journal of Educational Statistics, 1, 113-125.

Gustafsson, J. E. (1988). Hierarchical models of individual differences in cognitive abilities. In R. J. Sternberg (Ed.), Advances in the psychology of human intelligence (pp. 35-71). Hillsdale, NJ: Erlbaum.

Hembree, R. (1990). The nature, effects, and relief of mathematics anxiety. Journal for Research in Mathematics Education, 21, 33-46. 
Hyde, J. S., Fennema, E., Ryan, M., Frost, L. A., \& Hopp, C. (1990). Gender comparisons of mathematics attitudes and effect: A meta-analysis. Psychology of Women Quarterly, 14, 299-324.

Hopko, D. R., Mahadevan, R., Bare, R. L., \& Hunt, M. A. (2003). The Abbreviated Math Anxiety Scale (AMAS): Construction, validity, and reliability. Assessment, 10, 178182.

Hu, L., \& Bentler, P. M. (1999). Cutoff criteria for fit indexes in covariance structure analysis: Conventional criteria versus new alternatives. Structural Equation Modeling, 6, 1-55.

Hubbard, E. M., Piazza, M., Pinel, P., \& Dehaene, S. (2005). Interactions between number and space in parietal cortex. Nature Reviews Neuroscience, 6(6), 435-448.

Hunt, T. E., Clark-Carter, D., \& Sheffield, D. (2011). The development and part validation of a U.K. Scale for mathematics anxiety. Journal of Psychoeducational Assessment, 29(5), 455-466.

Jackson, D. L., Gillapsy, J. A. Jr., \& Purc-Stephenson, R. (2009). Reporting practices in confirmatory factor analysis: An overview and some recommendations. Psychological Methods, 14(1), 6-23.

Kline, P. (2000). The handbook of psychological testing (2nd Ed.). Routledge: London and New York.

LeFevre, J. A., Kulak, A.G, \& Heymans, S. L. (1992). Factors influencing the selection of university majors varying in mathematical content. Canadian Journal of Behavioural Science, 24(3), 276-289. 
LeFevre, J. A., Sadesky, G. S, \& Bisanz, J. (1996). Selection of procedures in mental addition: reassessing the problem size effect in adults. Journal of Experimental Psychology: Learning, Memory and Cognition, 1, 216-230.

Mulaik, S. A., James, L. R., Van Altine, J., Bennett, N., Lind, S., \& Stilwell, C. D. (1989). Evaluation of goodness-of-fit indices for structural equation models. Psychological Bulletin, 105, 430-445.

Plake, B. S., \& Parker, C. S. (1982). The development and validation of a revised version of the Mathematics Anxiety Rating Scale. Educational and Psychological Measurement, 42, 551-557.

Priftis, K., Piccione, F., Giorgi, F., Meneghello, F., Umiltà, C., \& Zorzi, M. (2008). Lost in number space after right brain damage: A neural signature of representational neglect. Cortex, 44(4), 449-453

Richardson, F. C., \& Suinn, R. M. (1972). The Mathematics Anxiety Rating Scale: Psychometric data. Journal of Counseling Psychology, 19, 551-554.

Rosenthal, R., \& Rosnow, R. L. (1984). Essentials of behavioral research. New York: McGraw-Hill.

Sandman, R. S. (1980). The mathematics attitude inventory: Instrument and user's manual. Journal for Research in Mathematics Education, 11, 148-149.

Schumacker, R. E., \& Lomax, R. G. (2004). A beginner's guide to structural equation modeling (2nd ed.). Mahwah, NJ: Lawrence Erlbaum Associates, Inc.

Sloan, J., Slane, S., Ashcraft, M. H., \& Fleck, D. E. (1994). Testing mathematics anxiety: The sMARS. Unpublished manuscript.

Spielberger, C. D., Gorsuch, R., Lushene, R., Vagg, P. R., \& Jacobs, G. A. (1983). Manual for the State-Trait Anxiety Inventory. Palo Alto, CA: Consulting Psychologists 
Press. Spanish adaptation of the STAI by TEA Ediciones S.A. ( $3^{\text {rd }}$ Edition). Madrid, 1988.

Steiger, J. H. (1980). Tests for comparing elements of a correlation matrix. Psychological Bulletin, 87,245-251.

Taylor, J. A. (1953). A personality scale of manifest anxiety. Journal of Abnormal and Social Psychology, 48, 285-290.

Thurstone, L. L. (1939). Manual of Instructions for the Primary Mental Abilities Test. Washington, D.C.: American Council of Education. Spanish adaptation of the PMA by TEA Ediciones S.A. (8th Edition). Madrid, 1989.

Tukey, J. W. (1953). The problem of multiple comparisons. Mimeographed monograph.

Welch, B. L. (1951). On the comparison of several mean values: An alternative approach. Biometrika, 38, 330-336. 
Table 1

Mean and standard deviation (in brackets) for age and sMARS scores for the sample disaggregated by gender and high-school itinerary. Percentage of sample for each category is also provided.

\begin{tabular}{lcccccc}
\hline & & Social & Science & Humanities & Technology & Others \\
\hline Men & $\%$ & $22.44 \%$ & $22.53 \%$ & $21.66 \%$ & $40.00 \%$ & $18.18 \%$ \\
& Age & $21.71(3.66)$ & $20.44(1.78)$ & $21.08(2.01)$ & $20.00(1.69)$ & $22.02(4.19)$ \\
& sMARS & $67.18(14.20)$ & $54.13(14.00)$ & $68.92(18.41)$ & $50.75(12.55)$ & $68.50(10.60)$ \\
\hline Women & $\%$ & $77.55 \%$ & $77.46 \%$ & $78.33 \%$ & $60.00 \%$ & $81.81 \%$ \\
& Age & $19.92(1.96)$ & $20.15(2.08)$ & $21.17(3.73)$ & $21.08(2.61)$ & $23.89(7.50)$ \\
& sMARS & $67.50(15.57)$ & $61.80(17.10)$ & $73.85(14.73)$ & $47.33(11.58)$ & $74.11(18.61)$ \\
\hline
\end{tabular}


Table 2

Distribution of scores and reliability coefficients for the sMARS

\begin{tabular}{|c|c|c|c|c|c|c|c|}
\hline Subscale & Mean & SD & Range & $\begin{array}{l}\text { Missing } \\
(\%)\end{array}$ & $\begin{array}{l}\text { Cronbach's } \\
\text { alpha }\end{array}$ & $\begin{array}{l}\text { Corrected item- } \\
\text { total correlation } \\
\quad \text { (range) }\end{array}$ & ICC \\
\hline Math test & 46.42 & 11.37 & $15-73$ & 1.8 & .93 & $\begin{array}{l}\text { From } .39 \text { (item } \\
\text { 10) to } .83 \text { (item } 8)\end{array}$ & .73 \\
\hline $\begin{array}{l}\text { Numerical } \\
\text { task }\end{array}$ & 9.32 & 4.09 & $5-24$ & 0.0 & .88 & $\begin{array}{c}\text { From } .40 \text { (item } \\
\text { 16) to } .87 \text { (item } \\
18)\end{array}$ & .56 \\
\hline $\begin{array}{l}\text { Math } \\
\text { course }\end{array}$ & 9.32 & 4.06 & $5-25$ & 1.5 & .85 & $\begin{array}{c}\text { From } .54 \text { (item } \\
21) \text { to } .73 \text { (item } \\
25)\end{array}$ & .67 \\
\hline Total score & 65.09 & 16.91 & $25-115$ & 3.2 & .94 & $\begin{array}{l}\text { From } .32 \text { (item } \\
\text { 16) to } .75(\text { item } 8)\end{array}$ & .72 \\
\hline
\end{tabular}


Table 3

Factor loadings and fit indexes of the three first-order factor model

\begin{tabular}{|c|c|c|c|}
\hline Items & Math test & Numerical task & Math course \\
\hline 1 & .756 & & \\
\hline 2 & .542 & & \\
\hline 3 & .733 & & \\
\hline 4 & .684 & & \\
\hline 5 & .685 & & \\
\hline 6 & .703 & & \\
\hline 7 & .729 & & \\
\hline 8 & .829 & & \\
\hline 9 & .758 & & \\
\hline 10 & .482 & & \\
\hline 11 & .647 & & \\
\hline 12 & .500 & & \\
\hline 13 & .731 & & \\
\hline 14 & .772 & & \\
\hline 15 & .662 & & \\
\hline 16 & & .452 & \\
\hline 17 & & .800 & \\
\hline 18 & & .877 & \\
\hline 19 & & .849 & \\
\hline 20 & & .890 & \\
\hline 21 & & & .544 \\
\hline 22 & & & .726 \\
\hline 23 & & & .792 \\
\hline 24 & & & .784 \\
\hline 25 & & & .801 \\
\hline Goodne & & & \\
\hline$\chi^{2}$ & \multicolumn{3}{|c|}{$\chi^{2}(272)=841.169(p<.05)$} \\
\hline GFI & \multicolumn{3}{|c|}{.969} \\
\hline AGFI & \multicolumn{3}{|c|}{.963} \\
\hline PGFI & \multicolumn{3}{|c|}{.811} \\
\hline NFI & \multicolumn{3}{|c|}{.961} \\
\hline SRMR & \multicolumn{3}{|c|}{.080} \\
\hline
\end{tabular}


Note. GFI: goodness-of-fit index; AGFI: adjusted goodness-of-fit index; PGFI: parsimony goodness-of-fit index; NFI: normed fit index; SRMR: standardized root mean squared residual 
Table 4

Correlations between the SMARS and the other measures

\begin{tabular}{|c|c|c|c|c|c|c|c|c|c|c|}
\hline Subscale & $\begin{array}{l}\text { Verification } \\
\text { test (French } \\
\text { Kit) }(n=96)\end{array}$ & $\begin{array}{l}\text { Addition } \\
\text { simple } \\
\text { task } \\
(n=262)\end{array}$ & $\begin{array}{l}\text { STAI-S } \\
(n=260)\end{array}$ & $\begin{array}{l}\text { STAI-T } \\
(n=260)\end{array}$ & $\begin{array}{c}\text { PMA-S } \\
(n=87)\end{array}$ & $\begin{array}{l}\text { PMA-R } \\
(n=87)\end{array}$ & $\begin{array}{l}\text { PMA-V } \\
(n=86)\end{array}$ & $\begin{array}{l}\text { Enjoyment } \\
\quad(n=262)\end{array}$ & $\begin{array}{c}\text { Self- } \\
\text { confidence } \\
(n=262)\end{array}$ & $\begin{array}{l}\text { Motivation } \\
\quad(n=262)\end{array}$ \\
\hline Math test & $-.26 * *$ & $-.13 *$ & $.43 * *$ & $.36^{* *}$ & $-.24 *$ & -.19 & -.05 & $-.49 * *$ & $-.54 * *$ & $-.46^{* *}$ \\
\hline Numerical task & $-.38 * *$ & $-.13 *$ & $.37 * *$ & $.27 * *$ & -.14 & -.07 & -.06 & $-.41 * *$ & $-.38 * *$ & $-.36 * *$ \\
\hline Math course & $-.29 * *$ & -.06 & $.35 * *$ & $.27 * *$ & $-.32 * *$ & -.15 & $-.21 *$ & $-.36 * *$ & $-.37 * *$ & $-.37 * *$ \\
\hline Total score & $-.32 * *$ & $-.13 *$ & $.46^{* * *}$ & $.37 * *$ & $-.26 *$ & -.18 & -.11 & $-.52 * *$ & $-.54 * *$ & $-.48 * *$ \\
\hline
\end{tabular}

Note. STAI: State-Trait Anxiety Inventory, -S: State, -T: Trait; PMA: Primary Mental Abilities Test, -S: Spatial Visualization, -R:

Reasoning, -V: Verbal Comprehension 
Table 5

Comparisons between correlations.

\begin{tabular}{lcc}
\hline Comparison & $\mathrm{Z}$ score & $p$ value \\
\hline$r_{\mathrm{MT}, \mathrm{S}}-r_{\mathrm{NT}, \mathrm{S}}$ & -0.92 & 0.35 \\
$r_{\mathrm{MT}, \mathrm{S}}-r_{\mathrm{MC}, \mathrm{S}}$ & 0.89 & 0.37 \\
$r_{\mathrm{NT}, \mathrm{S}}-r_{\mathrm{MC}, \mathrm{S}}$ & 1.73 & 0.08 \\
$r_{\mathrm{MT}, \mathrm{V}}-r_{\mathrm{NT}, \mathrm{V}}$ & 0.09 & 0.92 \\
$r_{\mathrm{MT}, \mathrm{V}}-r_{\mathrm{MC}, \mathrm{V}}$ & 1.72 & 0.09 \\
$r_{\mathrm{NT}, \mathrm{V}}-r_{\mathrm{MC}, \mathrm{V}}$ & 1.45 & 0.15 \\
\hline
\end{tabular}

Note. MT: Math test anxiety, NTA: number task anxiety, MCA: math course anxiety, -S: Spatial Visualization subtest from the PMA, -V:

Verbal Comprehension subtest from the PMA 
Table 6

sMARS scores (means and standard deviations) by gender and high-school itinerary

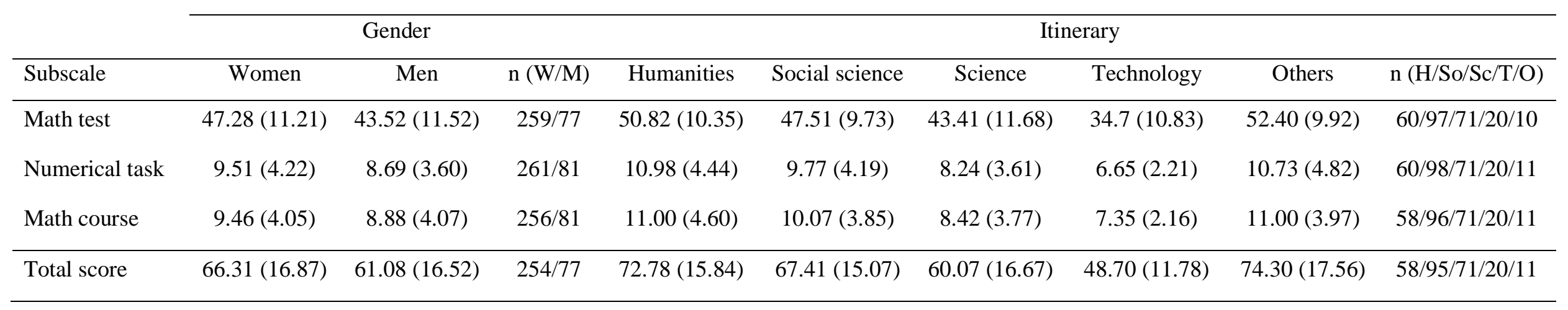

Note. W: women; M: men; H: humanities; So: social science; Sc: science; T: technology; O: others 
Table 7

Post hoc comparisons between high-school itineraries

\begin{tabular}{lcclcc}
\hline Comparison & $p$ value & $d$ value & Comparison & $p$ value & $d$ value \\
\hline Math task anxiety & & & Math course anxiety & \\
\hline H vs So & .315 & 0.33 & H vs So & .700 & 0.24 \\
H vs Sc & .001 & 0.67 & H vs Sc & .008 & 0.62 \\
H vs T & $<.001$ & 1.54 & H vs T & $<.001$ & 0.89 \\
H vs O & .992 & -0.15 & H vs O & 1.00 & 0.00 \\
So vs Sc & .095 & 0.39 & So vs Sc & .049 & 0.42 \\
So vs T & $<.001$ & 1.29 & So vs T & .001 & 0.73 \\
So vs O & .630 & -0.50 & So vs O & .944 & -0.26 \\
Sc vs T & .011 & 0.76 & Sc vs T & .486 & 0.31 \\
Sc vs O & .088 & -0.78 & Sc vs O & .312 & -0.68 \\
T vs O & $<.001$ & -1.68 & T vs O & .086 & -1.24 \\
\hline Numerical task anxiety & & & Total score & & \\
\hline H vs So & .442 & 0.28 & H vs So & .239 & 0.35 \\
H vs Sc & .002 & 0.68 & H vs Sc & $<.001$ & 0.78 \\
H vs T & $<.001$ & 1.08 & H vs T & $<.001$ & 1.62 \\
H vs O & 1.00 & 0.06 & H vs O & .999 & -0.09 \\
So vs Sc & .085 & 0.39 & So vs Sc & .025 & 0.47 \\
So vs T & .001 & 0.79 & So vs T & .001 & 1.29 \\
So vs O & .967 & -0.22 & So vs O & .673 & -0.45 \\
Sc vs T & .124 & 0.47 & Sc vs T & 0.72 \\
Sc vs O & -0.66 & Sc vs O & -0.85 \\
T vs O & -1.21 & T vs O & -1.81 \\
\hline
\end{tabular}

Note. H: humanities; So: social science; Sc: science; T: technology; O: others 


\section{Appendix 1}

\section{Spanish version of the sMARS}

Los ítems de este cuestionario se refieren a experiencias que pueden causar tensión o aprensión. Para cada ítem señala cuán ansioso/a te pondría cada una de ellas. Responde de forma rápida, pero asegúrate de pensar bien la respuesta. Es muy importante responder a todos los ítems.

\begin{tabular}{|c|c|c|c|c|c|}
\hline & Nada & $\begin{array}{l}\text { Muy } \\
\text { poco }\end{array}$ & Algo & Bastante & Mucho \\
\hline 1. Estudiar para un examen de matemáticas. & 1 & 2 & 3 & 4 & 5 \\
\hline $\begin{array}{l}\text { 2. Examinarme de matemáticas en las pruebas de acceso a la } \\
\text { universidad. }\end{array}$ & 1 & 2 & 3 & 4 & 5 \\
\hline 3. Hacer un control de matemáticas. & 1 & 2 & 3 & 4 & 5 \\
\hline 4. Hacer el examen final de matemáticas. & 1 & 2 & 3 & 4 & 5 \\
\hline $\begin{array}{l}\text { 5. Coger el libro de matemáticas para empezar a hacer los } \\
\text { deberes. }\end{array}$ & 1 & 2 & 3 & 4 & 5 \\
\hline $\begin{array}{l}\text { 6. Tener deberes con muchos problemas difíciles que han de } \\
\text { entregarse en la próxima clase. }\end{array}$ & 1 & 2 & 3 & 4 & 5 \\
\hline $\begin{array}{l}\text { 7. Pensar en el examen de matemáticas que tendré dentro de } 1 \\
\text { semana. }\end{array}$ & 1 & 2 & 3 & 4 & 5 \\
\hline 8. Pensar en el examen de matemáticas que tendré en 1 día. & 1 & 2 & 3 & 4 & 5 \\
\hline 9. Pensar en el examen de matemáticas que tendré en 1 hora. & 1 & 2 & 3 & 4 & 5 \\
\hline $\begin{array}{l}\text { 10. Darme cuenta de que se debe hacer un cierto número de } \\
\text { clases de matemáticas para cumplir con los requisitos } \\
\text { académicos. }\end{array}$ & 1 & 2 & 3 & 4 & 5 \\
\hline $\begin{array}{l}\text { 11. Coger un libro de matemáticas para comenzar una lectura } \\
\text { difícil que se me ha pedido. }\end{array}$ & 1 & 2 & 3 & 4 & 5 \\
\hline 12. Recibir por e-mail la nota final de matemáticas. & 1 & 2 & 3 & 4 & 5 \\
\hline $\begin{array}{l}\text { 13. Abrir un libro de matemáticas o de estadística y ver una } \\
\text { página llena de problemas. }\end{array}$ & 1 & 2 & 3 & 4 & 5 \\
\hline 14. Prepararme para estudiar para un examen de matemáticas. & 1 & 2 & 3 & 4 & 5 \\
\hline 15. Tener que hacer un examen sorpresa de matemáticas. & 1 & 2 & 3 & 4 & 5 \\
\hline 16. Revisar el ticket de compra después de haber pagado. & 1 & 2 & 3 & 4 & 5 \\
\hline $\begin{array}{l}\text { 17. Que me den una serie de problemas numéricos que } \\
\text { incluyan sumas para que los resuelva con papel y lápiz. }\end{array}$ & 1 & 2 & 3 & 4 & 5 \\
\hline 18. Que me den a resolver una serie de restas. & 1 & 2 & 3 & 4 & 5 \\
\hline 19. Que me den a resolver una serie de multiplicaciones. & 1 & 2 & 3 & 4 & 5 \\
\hline 20. Que me den a resolver una serie de divisiones. & 1 & 2 & 3 & 4 & 5 \\
\hline 21. Comprar un libro de matemáticas. & 1 & 2 & 3 & 4 & 5 \\
\hline $\begin{array}{l}\text { 22. Ver al profesor resolviendo una ecuación algebraica en la } \\
\text { pizarra. }\end{array}$ & 1 & 2 & 3 & 4 & 5 \\
\hline 23. Matricularme en un curso de matemáticas. & 1 & 2 & 3 & 4 & 5 \\
\hline
\end{tabular}




\begin{tabular}{|l|c|c|c|c|c|}
\hline $\begin{array}{l}\text { 24. Escuchar a otro alumno que explica una fórmula } \\
\text { matemática. }\end{array}$ & 1 & 2 & 3 & 4 & 5 \\
\hline 25. Entrar en una clase de matemáticas. & 1 & 2 & 3 & 4 & 5 \\
\hline
\end{tabular}

